\title{
Development of efficient catharanthus roseus regeneration and transformation system using agrobacterium tumefaciens and hypocotyls as explants
}

Quan Wang ${ }^{\dagger}$, Shihai Xing ${ }^{\dagger}$, Qifang Pan, Fang Yuan, Jingya Zhao, Yuesheng Tian, Yu Chen, Guofeng Wang and Kexuan Tang ${ }^{*}$

\begin{abstract}
Background: As a valuable medicinal plant, Madagascar periwinkle (Catharanthus roseus) produces many terpenoid indole alkaloids (TIAs), such as vindoline, ajamlicine, serpentine, catharanthine, vinblastine and vincristine et al. Some of them are important components of drugs treating cancer and hypertension. However, the yields of these TIAs are low in wild-type plants, and the total chemical synthesis is impractical in large scale due to high-cost and their complicated structures. The recent development of metabolic engineering strategy offers a promising solution. In order to improve the production of TIAs in C. roseus, the establishment of an efficient genetic transformation method is required.

Results: To develop a genetic transformation method for C. roseus, Agrobacterium tumefaciens strain EHA105 was employed which harbors a binary vector pCAMBIA2301 containing a report $\beta$-glucuronidase (GUS) gene and a selectable marker neomycin phosphotransferase II gene (NTPII). The influential factors were investigated systematically and the optimal transformation condition was achieved using hypocotyls as explants, including the sonication treatment of 10 min with $80 \mathrm{~W}$, A. tumefaciens infection of $30 \mathrm{~min}$ and co-cultivation of $2 \mathrm{~d}$ in 1/2 MS medium containing $100 \mu \mathrm{M}$ acetosyringone. With a series of selection in callus, shoot and root inducing kanamycin-containing resistance media, we successfully obtained stable transgenic regeneration plants. The expression of GUS gene was confirmed by histochemistry, polymerase chain reaction, and genomic southern blot analysis. To prove the efficiency of the established genetic transformation system, the rate-limiting gene in TIAs biosynthetic pathway, DAT, which encodes deacetylvindoline-4-O-acetyltransferase, was transferred into C. roseus using this established system and 9 independent transgenic plants were obtained. The results of metabolite analysis using high performance liquid chromatography (HPLC) showed that overexpression of DAT increased the yield of vindoline in transgenic plants.

(Continued on next page)
\end{abstract}

\footnotetext{
*Correspondence: kxtang@sjtu.edu.cn

${ }^{\dagger}$ Equal contributors

Plant Biotechnology Research Center, SJTU-Cornell Institute of Sustainable Agriculture and Biotechnology, Fudan-SJTU-Nottingham Plant Biotechnology R\&D Center, School of Agriculture and Biology, Shanghai Jiao Tong University, 800 Dongchuan Road, Minhang District, Shanghai 200240, China
} 
(Continued from previous page)

Conclusions: In the present study, we report an efficient Agrobacterium-mediated transformation system for C. roseus plants with $11 \%$ of transformation frequency. To our knowledge, this is the first report on the establishment of $A$. tumefaciens mediated transformation and regeneration of C. roseus. More importantly, the C. roseus transformation system developed in this work was confirmed in the successful transformation of C. roseus using a key gene DAT involved in TIAs biosynthetic pathway resulting in the higher accumulation of vindoline in transgenic plants.

Keywords: Catharanthus roseus, Agrobacterium tumefaciens, Deacetylvindoline-4-O-acetyltransferase, Regeneration, Vindoline

\section{Background}

Madagascar periwinkle (Catharanthus roseus) has become a model plant for secondary metabolism studies [1]. The medicinal plant $C$. roseus possesses a large number of terpenoid indole alkaloids (TIAs) among which over 130 compounds have been isolated and identified [2]. The production of the most valuable dimeric alkaloids vinblastine and vincristine are extremely low in wild-type $C$. roseus plant [3], and hard to be improved using cell suspension and hairy root cultures systems [4]. In addition, it is also difficult to synthesize TIAs by chemical methods due to their complicated structures [5]. Until now, the TIAs metabolic pathway (Figure 1) of C. roseus has become clearer. Vinblastine and vincristine are the most important antitumor bisindole alkaloids, which are derived from the coupling of vindoline and catharanthine monomers. The biochemical synthesis of the six-step enzymatic conversion of tabersonine to vindoline has been studied extensively [6]. The terminal step of vindoline biosynthesis is catalyzed by deacetylvindoline-4-O-acetyltransferase (DAT). The recent development of metabolic engineering strategy offers a promising solution to improve the TIAs production in $C$. roseus. Therefore, the establishment of effective regeneration and transformation system for $C$. roseus is required.

To date, genetic transformation of $C$. roseus has been mostly confined to hairy roots and suspension cells. Agrobacterium rhizogenes-mediated transformation involving productions of hairy (transgenic) roots in $C$. roseus had been reported $[4,7,8]$. However, the phenotypes of transgenic $C$. roseus plants transformed by $A$. rhizogenes are abnormal, such as shortened internodes, wrinkled leaves and abundant root mass [7]. Thus this kind of transgenic C. roseus plants is not suitable for the production of TIAs. Transgenic $C$. roseus cell suspension cultures transformed by either Agrobacterium infection or by particle bombardment had been established and studied intensively [4,9-13]. But these transgenic cells lines do not produce alkaloids in a stable manner and their ability to accumulate TIAs is gradually declined by long-term subculture [14]. Recently A. tumefaciens-mediated transformation was employed in C. roseus, the transgenic callus and plants were obtained respectively $[15,16]$. However, these transformation systems were not confirmed with other biochemical assays such as southern blot and high performance liquid chromatography (HPLC). To address these issues, in the present study we developed an A. tumfaciens mediated transformation and regeneration system of $C$. roseus. The stable regeneration plants were successfully acquired. To demonstrate this transformation system, $D A T$, an essential gene in TIAs biosynthetic pathway was overexpressed and the accumulation of vindoline was analyzed using HPLC in transformants.

\section{Results and discussion}

\section{Optimization of transformation conditions for $C$. roseus}

To develop an efficient system for producing transgenic $C$. roseus plants using $A$. tumefaciens, the association parameters were systemically investigated and optimized, including the concentration of Agrobacterium and acetosyringone, co-cultivation duration, and sonication condition. The detection was performed using the $A$. tumefaciens-mediated GUS gene transient expression. The transformation frequency was calculated as the number of kanamycin resistance plants/number of explants $\times 100$.

Firstly, we assessed the A. tumefaciens density and duration during infection. The density of $A$. tumefaciens culture corresponding to $\mathrm{OD}_{600}=0.5,0.8$ and 1.0 were chosen. These A. tumefaciens cultures were re-suspended to $\mathrm{OD}_{600}=0.5$ with liquid MS supplied with $100 \mu \mathrm{M}$ acetosyringone. Then the hypocotyls were treated for 15, 30 and 45 min respectively. The results showed that the highest GUS transient expression (100\%) and the relatively lower death rate for the explants (15\%) were achieved using the $\mathrm{OD}_{600}=0.8$ of $A$. tumefaciens and the explants infection of $30 \mathrm{~min}$ (Table 1).

Secondly, the effects of co-cultivation duration and acetosyringone concentration on transformation frequency were optimized separately. The co-cultivation with A. tumefaciens between 1 to $3 \mathrm{~d}$ and the acetosyringone concentration $(0,50,100$ and $150 \mu \mathrm{M})$ on T-DNA delivery were tested. The results showed that the highest frequency of GUS transient expression (100\%) and the relatively lower death rate $(5 \%)$ were obtained for the explants with $2 \mathrm{~d}$ co-cultivation and $100 \mu \mathrm{M}$ of acetosyringone in co-culture medium in dark (Table 1). 


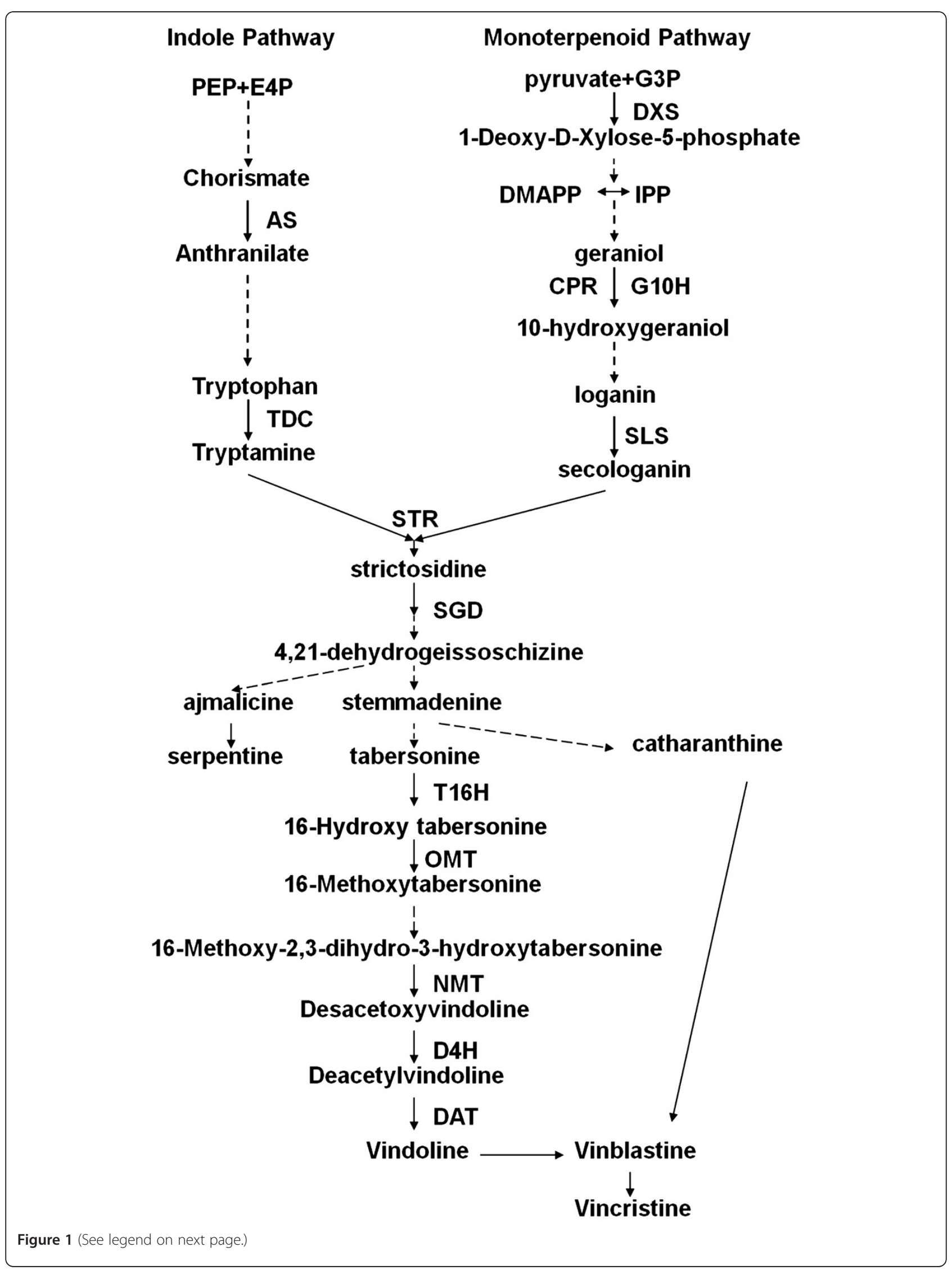


(See figure on previous page.)

Figure 1 Biosynthesis of $\boldsymbol{C}$. roseus TIAs. The abbreviations stand for anthranilate synthase (AS), tryptophan decarboxylase (TDC), geraniol-10hydroxylase $(\mathrm{G} 1 \mathrm{OH})$, cytochrome P450 reductase (CPR), secologanin synthase (SLS), strictosidine synthase (STR), strictosidine $\beta$-D-glucosidase (SGD), tabersonine-16-hydroxylase (T16H), 16-hydroxytabersonine-16-O-methyltransferase (16-OMT), minovincinine-19-O-acetyltransferase (MAT), desacetoxyvindoline-4-hydroxylase (D4H), deacetylvindoline-4-O-acetyltransferase (DAT), and Peroxidase (PRX). Broken arrows indicate multiplestep or uncharacterized enzymatic conversions.

Thirdly, the effects of sonication power and time on transformation frequency were investigated. Agrobacterium provides one of the main vehicles for introducing foreign DNA into plants based on its Ti-plasmid. However, one disadvantage of Agrobacterium transformation is the host's specificity, which results in low efficiency in certain species [17]. Sonication-assisted Agrobacterium-mediated transformation (SAAT) offers an option to enhance Agrobacterium transient or stable transformation efficiency in different plant tissues [18]. The explanation might be the micro wounding formed by sonication on the surface and sub-surface layers of targeted tissue, which secrets more phenolic compounds and enhances the efficiency of transformation [19]. Up to now, the SAAT has been successfully employed to enhance transformation efficiency in several plant species, including kidney bean [20], radish [21], flax [22] and chickpea [23]. However, sonication alone has its negative effects on survival rate of the explants. So in this work the intensity and period of sonication were evaluated in order to seek the optimization of sonication application on C. roseus transformation. Before A. tumefaciens infection, $C$. roseus hypocotyls were transferred into liquid MS medium with $100 \mu \mathrm{M}$ acetosyringone, and then sonicated with different power $(0,60,80$ and $100 \mathrm{~W})$ and time $(5,10$ and $15 \mathrm{~min})$, respectively. The results are shown as Figure 2. After $2 \mathrm{~d}$ co-cultivation, we found that the transient expression of GUS stain was enhanced with the increase of sonication time and power (data not show). This result indicated that the transient transformation efficiency can be improved with the sonication treatment, which is accord with previous reports $[12,16]$. The growth of explants was further observed by transferring them to the MSCP1 culture medium (Table 2). The sonication power of $0 \sim 60 \mathrm{~W}$ and $0 \sim 15 \mathrm{~min}$ had no influence on the survival rate of these explants (Figure 2). However, the survival rate was decreased to $45 \%$ when the ultrasound treatment increased to $80 \mathrm{~W}$ and $15 \mathrm{~min}$. Furthermore, when the sonication

Table 1 Influence of transformation factors on the frequency of transient GUS expression (\%) in hypocotyls of C. roseus

\begin{tabular}{|c|c|c|c|c|}
\hline \multirow{2}{*}{$\begin{array}{l}\text { Factors } \\
\text { A. tumefaciens infection density(OD) and duration (min) }\end{array}$} & \multicolumn{2}{|c|}{ Variable } & \multirow{2}{*}{$\begin{array}{l}\begin{array}{l}\text { Transient expression rate }(\%)^{\mathrm{a}} \\
(\text { mean } \pm \mathrm{SE})^{\mathrm{c}}\end{array} \\
53.33 \pm 3.33 \mathrm{C}\end{array}$} & \multirow{2}{*}{$\begin{array}{l}\begin{array}{l}\text { Death rate }(\%) \\
(\mathrm{mean} \pm \mathrm{SE})^{\mathbf{b}}\end{array} \\
10.00 \pm 2.89 \mathrm{~b}\end{array}$} \\
\hline & 0.5 & 15 & & \\
\hline & & 30 & $78.33 \pm 4.41 \mathrm{ab}$ & $11.67 \pm 1.67 \mathrm{a}$ \\
\hline & & 45 & $80.00 \pm 2.89 a$ & $11.67 \pm 3.33 \mathrm{a}$ \\
\hline & 0.8 & 15 & $78.33 \pm 3.33 b$ & $15.00 \pm 1.67 b$ \\
\hline & & 30 & $100.00 \pm 0.00 \mathrm{a}$ & $15.00 \pm 2.89 b$ \\
\hline & & 45 & $100.00 \pm 0.00 \mathrm{a}$ & $21.67 \pm 1.67 \mathrm{a}$ \\
\hline & 1.0 & 15 & $73.33 \pm 1.67 b$ & $18.33 \pm 3.33 c$ \\
\hline & & 30 & $100.00 \pm 0.00 \mathrm{a}$ & $46.66 \pm 6.01 b$ \\
\hline & & 45 & $100.00 \pm 0.00 \mathrm{a}$ & $68.33 \pm 4.41 \mathrm{a}$ \\
\hline \multirow[t]{3}{*}{ Co-cultivation period (d) } & 1 & & $76.67 \pm 4.41 b$ & $0.00 \pm 0.00 \mathrm{c}$ \\
\hline & 2 & & $100.00 \pm 0.00 \mathrm{a}$ & $5.00 \pm 2.89 b$ \\
\hline & 3 & & $100.00 \pm 0.00 \mathrm{a}$ & $20.00 \pm 5.77 a$ \\
\hline \multirow[t]{4}{*}{ Acetosyringone concentration ( $\mu \mathrm{M})$} & 0 & & $13.33 \pm 3.33 c$ & $0.00 \pm 0.00 \mathrm{~cd}$ \\
\hline & 50 & & $85.00 \pm 2.89 a b$ & $1.66 \pm 1.66 \mathrm{bc}$ \\
\hline & 100 & & $100.00 \pm 0.00 \mathrm{a}$ & $5.00 \pm 2.89 b$ \\
\hline & 150 & & $100.00 \pm 0.00 \mathrm{a}$ & $46.67 \pm 4.41 \mathrm{a}$ \\
\hline
\end{tabular}

Transient expression of GUS gene was examined after co-culture. The data of death rates were collected after $10 \mathrm{~d}$ of co-culture. Hypocotyls were placed on MSCP1 medium.

${ }^{\text {a }}$ Transient expression rate $=$ number of $\mathrm{GUS}^{+}$(GUS-positive) explants/number of explants $\times 100$.

${ }^{b}$ Death rate $=$ number of died explants/number of explants $\times 100$.

${ }^{c}$ Values represent means for 60 explants per treatment, replicated three times. Mean \pm SE in each column followed by the same letter are not significantly different according to Tukey's multiple comparison test $(P \leq 0.05)$. 


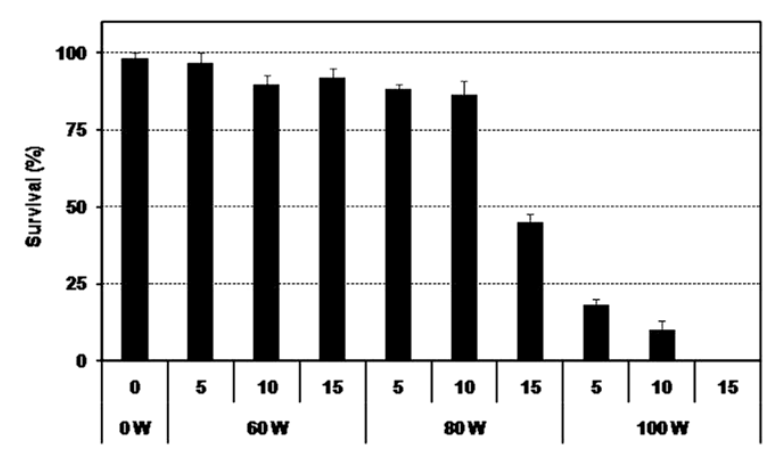

Figure 2 Effect of sonication intensity and time on the survival rate of hypocotyls after 10 days in MSCP1 medium. Survival rate of explants was evaluated at 10 days after co-cultivation. Only the green explants were taken into account, and the withered were thought as non-survival. Survival rate= number of green explants/ number of total explants $\times 100$.

power arrived at $100 \mathrm{~W}$, the survival rate of explants was decreased remarkably. Altogether, the sonication treatment of $80 \mathrm{~W}$ and $10 \mathrm{~min}$ can improve the transformation efficiency of $C$. roseus while keeping relatively high surviving rate $(85 \%)$.

Fourthly, the influence of kanamycin concentration on plant regeneration was assessed. The types of selectable markers and the selection pressure are very important factors for successful transformation [24]. The neomycin phosphotransferase gene which confers on the plant resistance to kanamycin is used in this protocol. Selection during callus induction and shoot initiation encourages regeneration of putative transgenic plants [25]. In the present study, three media (MSCP1, MSCP2 and MSCP3) (Table 2) supplied with different concentrations of kanamycin (Table 3) were prepared and used in sequence. Considering the growth of plant itself may strengthen resistance to kanamycin, the relatively higher kanamycin concentration was used in the media from MSCP1 to MSCP3.

From Figure 3A, the regeneration frequency of transformed and non-transformed explants was declined with the increase of kanamycin concentration. With the kanamycin concentration of $40 \mathrm{mg} / \mathrm{L}$ in MSCP1 and $50 \mathrm{mg} / \mathrm{L}$ in MSCP2 (K1-K3 treatment), the differentiation of non-

Table 2 The regeneration mediums used in this study

\begin{tabular}{ll}
\hline Mediums & The components of the medium \\
\hline MSCP & MS $+150 \mathrm{mg} / \mathrm{L}$ casein hydrolysate $+250 \mathrm{mg} / \mathrm{L}$ \\
& $\mathrm{L}$-proline $+30 \mathrm{~g} / \mathrm{L}$ sucrose $+3 \mathrm{~g} / \mathrm{L}$ gelrite \\
MSCP1 & $\mathrm{MSCP}+1.0 \mathrm{mg} / \mathrm{L} 2,4-\mathrm{D}+1.0 \mathrm{mg} / \mathrm{L} \mathrm{NAA}+0.1 \mathrm{mg} / \mathrm{L}$ \\
& $\mathrm{ZT}+250 \mathrm{mg} / \mathrm{L} \mathrm{carbenicillin}$ \\
MSCP2 & MSCP $+5.0 \mathrm{mg} / \mathrm{L} \mathrm{BA}+0.5 \mathrm{mg} / \mathrm{L} \mathrm{NAA}+250 \mathrm{mg} / \mathrm{L}$ \\
& carbenicillin \\
MSCP3 & MSCP $+1.75 \mathrm{mg} / \mathrm{L} \mathrm{BA}+0.55 \mathrm{mg} / \mathrm{L} \mathrm{IAA}+250 \mathrm{mg} / \mathrm{L}$ \\
& carbenicillin \\
\hline
\end{tabular}

Table 3 Experimental design for kanamycin concentration optimization

\begin{tabular}{llll}
\hline Treatment & $\begin{array}{l}\text { Kan concentration } \\
\text { of MSCP1 (mg/L) }\end{array}$ & $\begin{array}{l}\text { Kan concentration } \\
\text { of MSCP2 (mg/L) }\end{array}$ & $\begin{array}{l}\text { Kan concentration } \\
\text { of MSCP3 (mg/L) }\end{array}$ \\
\hline K1 & 40 & 50 & 70 \\
K2 & 40 & 50 & 90 \\
K3 & 40 & 50 & 110 \\
K4 & 40 & 70 & 70 \\
K5 & 40 & 70 & 90 \\
K6 & 40 & 70 & 110 \\
K7 & 40 & 90 & 90 \\
K8 & 40 & 90 & 110 \\
\hline
\end{tabular}

transformed explants was inhibited comparing to transformed explants. But the regeneration frequency of nontransformed explants is still from $13 \%$ to $23 \%$. When the kanamycin concentration higher than $70 \mathrm{mg} / \mathrm{L}$ in MSCP2 and $90 \mathrm{mg} / \mathrm{L}$ in MSCP3 (K5-K8 treatment), the regeneration of non-transformed explants was almost completed inhibited. The representative images are shown as in Figure 3B, which exhibit the contrast of growth state between non-transformed and transformed explants. At last, $40 \mathrm{mg} / \mathrm{L}$ in MSCP1, $70 \mathrm{mg} / \mathrm{L}$ in MSCP2 and $90 \mathrm{mg} / \mathrm{L}$ in MSCP3 kanamycin (K5 treatment) were used for selecting transformed plants due to the relatively high regeneration efficiency of transformed explants (11\%) and low regeneration efficiency of nontransformed explants (1\%).

\section{Regeneration of transgenic $C$. roseus}

Using hypocotyls as explants, callus induction, shoot initiation and root initiation media containing kanamycin were employed in sequence. After Agrobacteriummediated transformation and $2 \mathrm{~d}$ co-cultivation in dark, transgenic calli were induced by growing the hypocotyl explants for $10 \mathrm{~d}$ in selective medium (MSCP1) with kanamycin. Then the induced transgenic calli were subjected to additional two rounds of selection on medium (MSCP2 and MSCP3) containing higher levels of kanamycin (Figure 4A), which helps to eliminate falsepositive plants. In this experiment, we found most explants became brown gradually and died except the putative transformants. The green shoots of putative transformants that appeared in $40 \mathrm{~d}$ (Figure 4B) were transferred onto roots induction medium (Figure 4C). At last, the rooted plants grew normally after transplanted to soil in the green house (Figure 4D, E, and F). It took $3 \sim 4$ months using hypocotyls as starting materials from inoculation with $A$. tumefaciens to transplant to soil. The procedures of $C$. roseus transformation were showed in Figure 5. 


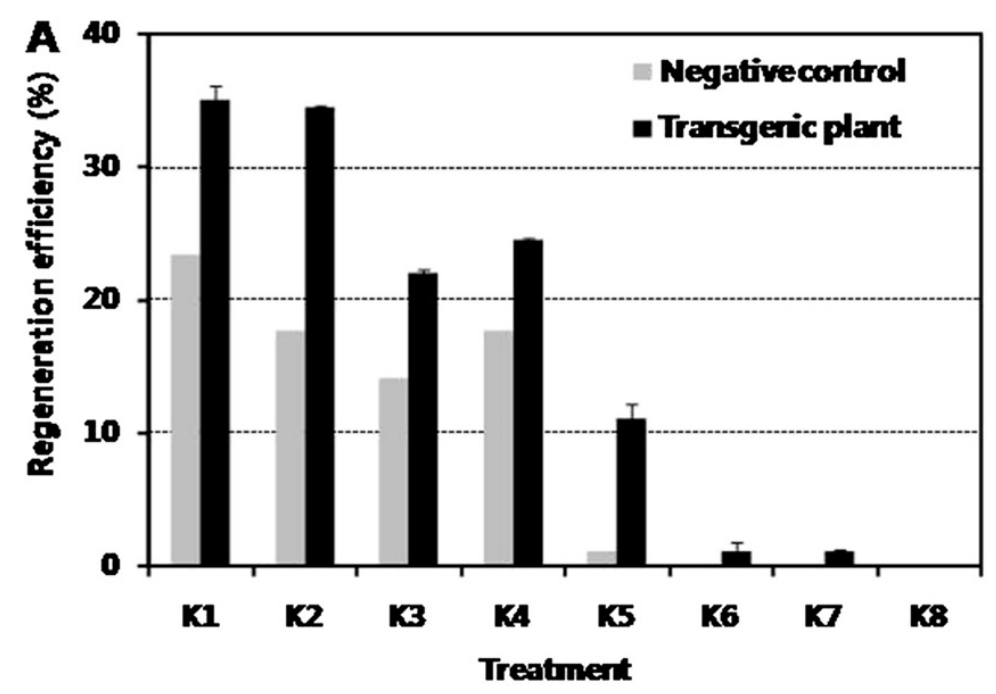

B

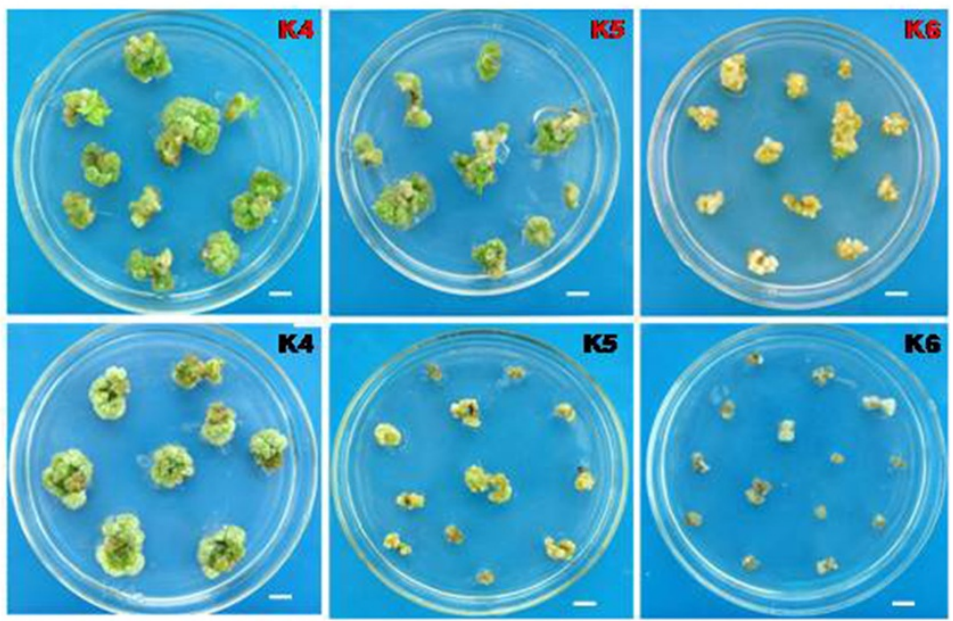

Figure 3 Influence of kanamycin concentration on the regeneration of $C$. roseus in shoot elongation (MSCP3) medium. A K1-K8 represent culture conditions with different kanamycin concentrations. Regeneration efficiency = number of regeneration explants/number of total explants $\times 100$. B The red words represent Agrobacterium-mediated transformation with resistant strains, and the black words represent Agrobacterium-mediated transformation with non-resistant strains. The pictures were taken at the $30^{\text {th }}$ day after co-culture in shoot elongation medium. Scale bar $=0.9 \mathrm{~cm}$.

\section{Molecular characterization of transgenic $C$. roseus plants} with GUS

To confirm the transformation events, histochemical analysis of GUS activity was carried out in putative kanamycin resistant transgenic lines. GUS positive blue coloration was visibly detected in all transgenic tissues stained with $\mathrm{X}$-gluc reagent (Figure 6B, C-right and D-left). However the GUS staining was not detected in the wild type plants which were neither sonicated nor transformed with Agrobacterium (Figure 6A, C-left and D-right).

To determine the presence and the integration of transgene in kanamycin resistant plants, PCR and DNA blot hybridization were performed with genomic DNA. First the putative transgenic plants were screened by
PCR using GUS gene-specific primers to detect the presence of target gene in host. The representative results are shown as in Figure 6E. It indicates the 400 bp fragments of GUS genes in kanamycin-resistant transformed plants were amplified, which is the same as positive control. No specific amplification product was detected in non-transgenic control plants.

The transgenic plant integrated with foreign gene was further verified by southern blot with the fragment of GUS as probe. The genomic DNA was obtained from two independent PCR-positive and GUS-positive transgenic $C$. roseus plants. The southern results indicate that the T-DNA was inserted into genome of both transgenic plants. One transgenic plant has a single copy and 


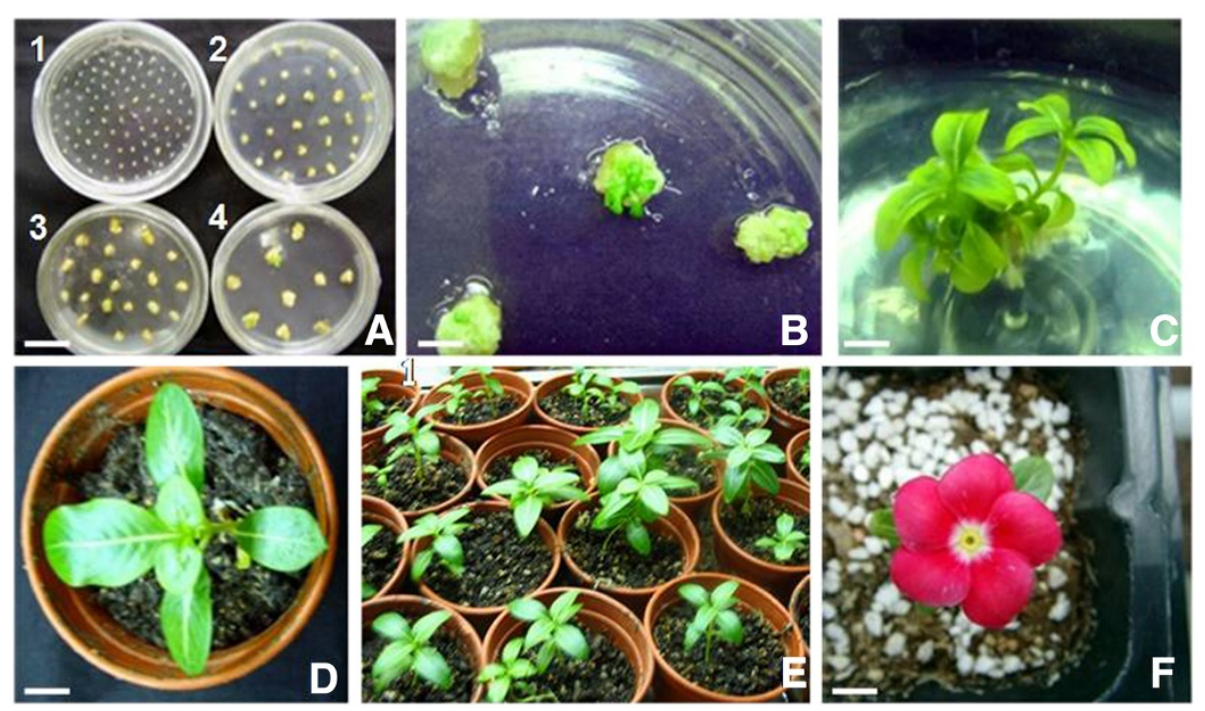

Figure 4 Regeneration and transformation of $\boldsymbol{C}$. roseus. A The regenerative phase of C. roseus (1: Sowing in MS medium; 2: Callus induction in MSCP1 medium; 3, 4: Shoots initiation in MSCP2 and MSCP3 medium separately). B Shooted plantlet. C Rooted plantlet. D, E Transgenic plantlets in soil. F Flower seedlings. Scale bar $=3 \mathrm{~cm}$ in $\mathbf{A}, 1 \mathrm{~cm}$ in $\mathbf{B}, \mathbf{F}, 2 \mathrm{~cm}$ in $\mathbf{C}$ and $1.5 \mathrm{~cm}$ in $\mathbf{D}$.

another has two copies, while no signal is detected in the untransformed control (Figure 6F).

Altogether, the results of molecular analyses confirm that these regenerated plants are stably integrated with GUS gene. In this study we obtained 16 putatively transformed plants by transformed the explants three times using same method. The percentage of explants producing regenerates was $19 \%$ and the frequency of explants producing independent transgenic plants was established at $11 \%$.

\section{Analysis of transgenic C. roseus plants with overexpressed DAT}

In order to validate the established transformation system, the DAT was over expressed in Catharanthus plants using the same transformation procedure. 9 independent transgenic plants were confirmed by southern blot and/or PCR analyses (Figure 7). With the fragment of $D A T$ as probe, the result of southern blot (Figure 7A) show that the transformants contained 1 to 2 more copies of $D A T$ gene than the negative control.

The DAT mRNA level was analyzed using real-time PCR in 9 independently $D A T$ transformed $C$. roseus plants. The results reveal that the expression level of $D A T$ was increased in all the transgenic plants (Figure 7B). Especially for $\mathrm{d} 31, \mathrm{~d} 35$ and $\mathrm{d} 42$ transgenic plants, the expression of $D A T$ was significantly increased by $7.64,6.14$ and 7.58 -fold respectively.

At last, the yield of vindoline was determined by HPLC in DAT overexpressed transgenic plants. The pCAMBIA2301 transgenic and wild type plants were served as negative controls. With DAT overexpression, the results show that the production of vindoline was increased in all transformants (Figure 8). The amount of vindoline was $1.42 \sim 2.72 \mu \mathrm{g} / \mathrm{mg}$ (DW) in transgenic plants with overexpressed DAT, and about $1.15 \mu \mathrm{g} / \mathrm{mg}$ (DW) in both pCAMBIA2301 and wild-type plants. Especially for the $\mathrm{d} 31$, the accumulated vindoline was $2.72 \mu \mathrm{g} / \mathrm{mg}$ (DW), 2.4folds than that of controls. This finding is consistent with the real-time PCR results, which suggests that DAT expression is associated with the accumulation of vindoline. However, further investigations will be needed involving more number of transformed plants to decipher the precise role of $D A T$ genes in the regulation of TIAs pathway in $C$. roseus.

Because the transformation of $C$. roseus at whole plant level had no report before, the functions of genes in TIAs were investigated using hair root or suspension cell transformation so far. Here the established transformation system provides a potential possibility to investigate the effect of gene expression upon the alkaloids yields on C. roseus whole plant, and would contribute to the successful modification of the medicinal plants for higher natural product yields.

\section{Conclusions}

Here we report an Agrobacterium-mediated transformation and regeneration system for $C$. roseus. The parameters influencing the transformation frequency are systematically investigated, including the concentration of Agrobacterium and acetosyringone, co-cultivation duration, sonication condition and selection pressure of kanamycin. The results show that the transformation frequency arrived at $11 \%$. In order to validate the established transformation system, the key gene, DAT, in TIAs biosynthetic pathway was 


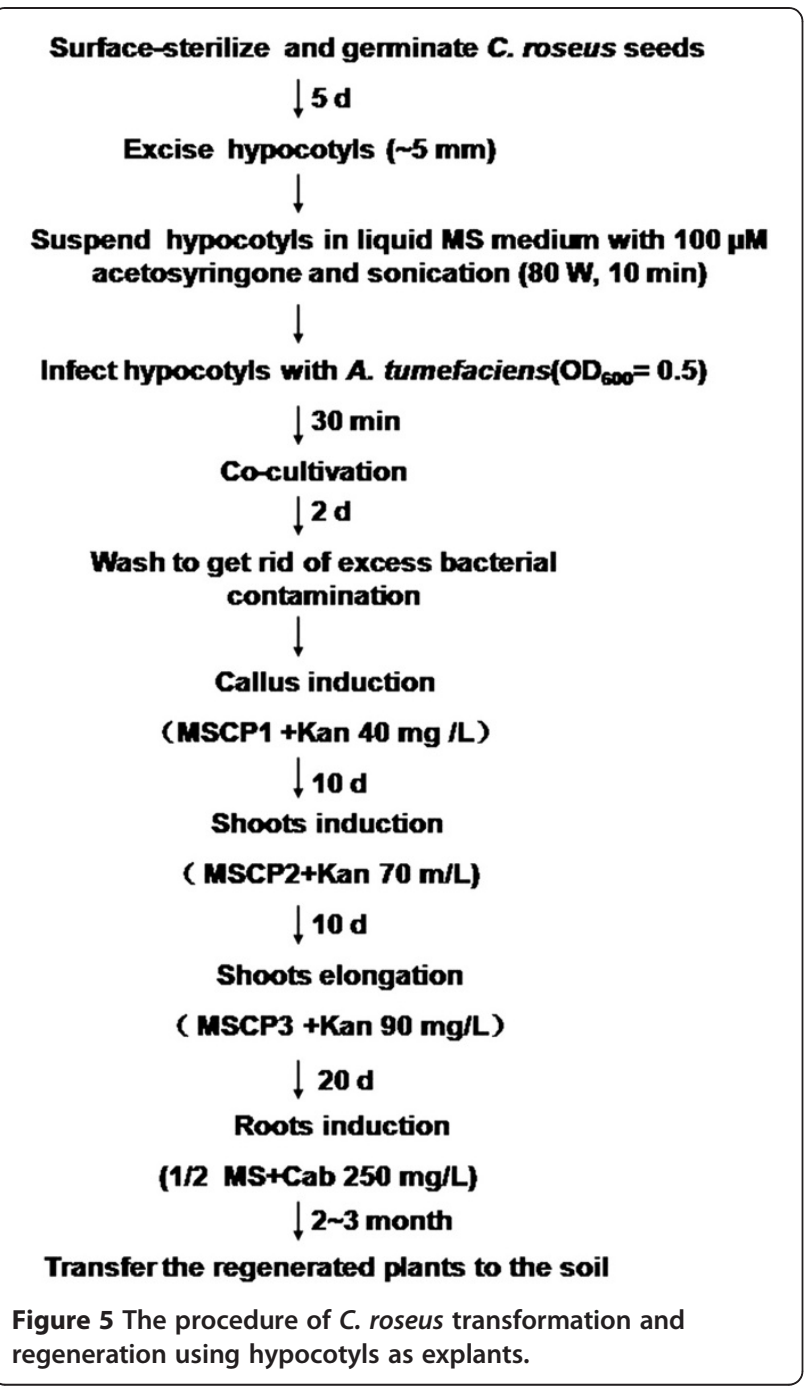

overexpressed. The HPLC results reveal that the production of vindoline was enhanced in transgenic plants with $D A T$ overexpression.

In conclusion, all the results obtained show that the $C$. roseus transformation protocols developed in this work has great potential to be used in the discovery of genes function in TIAs biosynthetic pathway, in addition to improve the productions of TIAs.

\section{Methods}

Plant material

Seeds of C. roseus cultivar Pacifica Cherry Red were purchased from PanAmerican Seed Company (USA). Seeds were sterilized with $75 \%(\mathrm{v} / \mathrm{v})$ ethanol for $1 \mathrm{~min}$ and $10 \%$ $(\mathrm{v} / \mathrm{v}) \mathrm{NaClO}$ for $10 \mathrm{~min}$, and then were washed three times with sterile distilled water. Finally, seeds were transferred onto Petri plates containing MS [24] basal medium. Cultures were germinated $16 \mathrm{~h}$ light and $8 \mathrm{~h}$ dark photoperiod at $25 \pm 2^{\circ} \mathrm{C}$. Hypocotyls, about $5 \mathrm{~mm}$, were excised from $5 \mathrm{~d}$-old germinated seedlings.

\section{A. tumefaciens strain and vector used for transformation} For transformation, A. tumefaciens strain EHA105 harbouring the binary pCAMBIA2301 (CAMBIA Company, Australia) was used for transformation. The vector contains a GUS reporter gene and a selection marker gene NPTII (neomycin phosphotransferase gene conferring resistance to kanamycin) which are inserted between the CaMV35S promoter and the A. tumefaciens nos terminator separately. An intron inside the coding sequence is included in the GUS reporter gene to ensure that expression of glucuroidase activity is derived from eukaryotic cells.

To get fresh cells, a single colony of $A$. tumefaciens with pCAMBIA2301 vector was inculcated in liquid Luria Bertani (LB) medium containing $100 \mathrm{mg} / \mathrm{L}$ kanamycin and $100 \mathrm{mg} / \mathrm{L}$ rifampicin (Sigma, USA), and grown at $28^{\circ} \mathrm{C}$ for $36 \mathrm{~h}$ with shaking $(150 \mathrm{rpm})$. The initial culture was diluted 1:1000 with liquid LB medium and grown on a shaker $(250 \mathrm{rpm})$ until the $\mathrm{OD}_{600}$ reached to $0.5,0.8$ and 1.0. Then the cells were centrifuged $(2,000 \times \mathrm{g}, 10 \mathrm{~min})$ and the supernatant was removed. The bacterium was re-suspended in liquid MS medium containing $100 \mu \mathrm{M}$ acetosyringone and the $\mathrm{OD}_{600}$ was adjusted to 0.5 . At last, the bacterium was shaken $(100 \mathrm{rpm})$ again for $2 \mathrm{~h}$ in dark at $28^{\circ} \mathrm{C}$.

\section{Genetic transformation and co-cultivation}

The explants of $C$. roseus were immersed in liquid MS medium with $100 \mu \mathrm{M}$ acetosyringone in tissue culture tubes. Then these tubes were sonicated for 5/10/15 $\mathrm{min}$ $(40 \mathrm{~Hz}, 0 / 60 / 80 / 100 \mathrm{~W})$ with the sonicator DL-60D (Shanghai hengxin, China) separately. After that, the explants were transferred into pre-sterilized flasks containing bacterial suspension, and were shaken gently at $25 \mathrm{rpm}$ for $30 \mathrm{~min}$ at room temperature. Explants were then blot-dried with sterile paper towels and transferred onto petri dishes containing 1/2 MS medium with $100 \mu \mathrm{M}$ acetosyringone. The co-cultivation period was $1 \sim 3 \mathrm{~d}$ in the dark at $28^{\circ} \mathrm{C}$.

\section{Plant regeneration}

After co-cultivation, the explants were transferred into

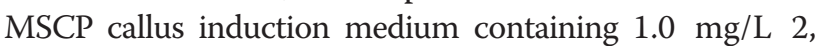
4-D, $1.0 \mathrm{mg} / \mathrm{L}$ NAA, $0.1 \mathrm{mg} / \mathrm{L} \mathrm{ZT,} 250 \mathrm{mg} / \mathrm{L}$ carbenicillin and $40 \mathrm{mg} / \mathrm{L}$ kanamycin (MSCP1 medium) for $10 \mathrm{~d}$. Then the explants were transferred to the MSCP medium supplemented with $5.0 \mathrm{mg} / \mathrm{L}$ 6-BA, $0.5 \mathrm{mg} / \mathrm{L}$ NAA, $250 \mathrm{mg} / \mathrm{L}$ carbenicillin and $70 \mathrm{mg} / \mathrm{L}$ kanamycin (MSCP2 medium), which was effective on shoot initiation for $10 \mathrm{~d}$. The resulting explants were transferred to shoot elongation MSCP medium supplemented with $1.75 \mathrm{mg} / \mathrm{L}$ 6-BA, $0.55 \mathrm{mg} / \mathrm{L}$ 

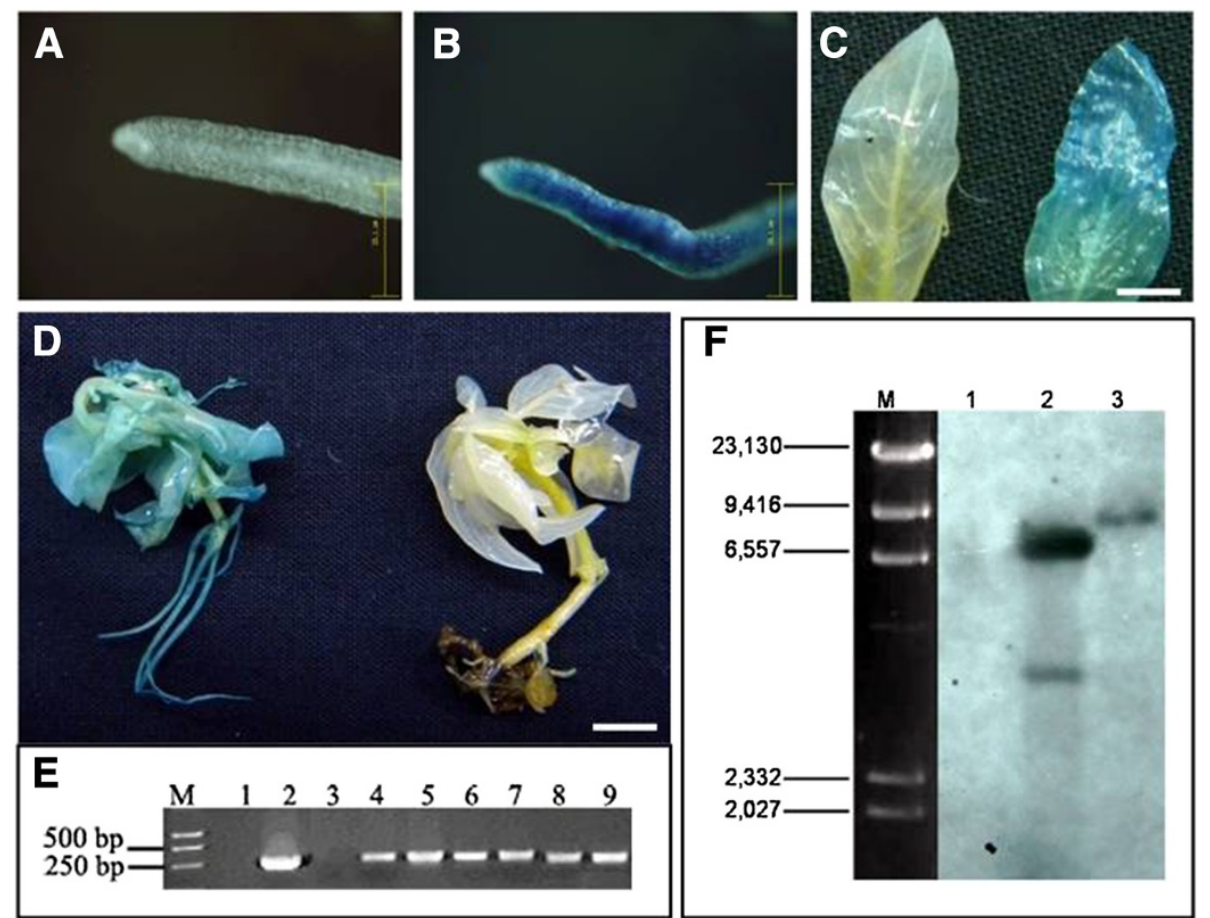

Figure 6 Analysis of transgenic GUS C. roseus. A-D Histochemical GUS expression in transgenic GUS plants of regenerated C. roseus. A, C-left, D-right: non-transformed control; B, C-right and D-left: transgenic plant. Scale bar $=25.1 \mu \mathrm{m}$ in $\mathbf{A}$ and $\mathbf{B}, 0.5 \mathrm{~cm}$ in $\mathbf{C}$ and $1 \mathrm{~cm}$ in $\mathbf{D}$. E Detection of GUS gene in kanamycin-resistant C. roseus plants using PCR. M, DL2000 DNA ladder (Maker from TaKaRa); 4-9, regenerated transgenic plant; 1, DNA from non-transformant (negative control); 2, pCAMBIA2301 was used as template (positive control); 3, $\mathrm{H}_{2} \mathrm{O}$ as template (negative control). $\mathbf{F}$ Southern-blot analysis of transgenic C. roseus plants. 1 is untransformed control plant; 2 and 3 are the DNA from two independed transformants digested by HindllI, respectively. M, $\lambda$-Hind III Marker.

IAA, $250 \mathrm{mg} / \mathrm{L}$ carbenicillin and $90 \mathrm{mg} / \mathrm{L}$ kanamycin (MSCP3 medium) for $20 \mathrm{~d}$, and subcultured every week. The elongated shoots were separated and transferred to root initiation medium (1/2 MS) containing $250 \mathrm{mg} / \mathrm{L}$ carbenicillin for $1 \sim 2$ months. The regeneration seedlings were removed from the growth cabinet and were transferred to gardening soil. All the culture conditions were performed as pre-described for the plant seeding.

\section{Analysis of putative transformants}

Histochemical GUS activities in leaf and root segments of the control and putatively transformed plantlets were investigated according to Jefferson [26]. Tissues were immersed in a buffer containing $2 \mathrm{mM} \mathrm{X}$-Gluc, $50 \mathrm{mM}$ phosphate, $50 \mathrm{mM}$ potassium ferrocyanide and $5 \%$ Trition $\mathrm{X}-100$ at $\mathrm{pH}$ 7.0. The reaction mixture was placed in a mild vacuum for $10 \mathrm{~min}$, and then incubated overnight at $37^{\circ} \mathrm{C}$. Tissues containing chlorophyll were repeatedly soaked in $95 \%$ ethanol until chlorophyll was removed. Transient expression of GUS gene was examined after $5 \mathrm{~d}$ of co-cultivation, while stable expression of the reporter gene was scanned after the C. roseus regeneration plants were transplanted to greenhouse for 3 months.
Genomic DNA was isolated from the young leaves of putative transgenic plants using CTAB method [27]. Putative transgenic plants were initially screened by PCR using the GUS gene-specific primers GUS FI (5'-GGGTGAAGGTTATCTCTATGAAC-3 $/$ ) and GUS RI (5/-CACTGATACTCTTCACTCCACAT-3/) to detect the presence of target gene in the host.

The integration of the GUS gene in the transgenic $C$. roseus was examined by southern hybridization. Approximately $50 \mu \mathrm{g}$ of genomic DNA per sample was digested with HindIII which was unique site in the plasmid. Then the digested DNA were fractionated by 1.0\%-agarose-gel electrophoresis, transferred onto a positively charged Hybond- $\mathrm{N}^{+}$nylon membrane (GE Heathcare, USA), and hybridized with an alkalinephosphatase-labelled partial cDNA sequence of GUS. The probe (402 bp) was generated by PCR with primers GUS FII (5/-CAGTCTTACTTCCATGATTTCTTTA-3') and GUS RII (5/-AGTAAAGTAGAACGGTTTGTGGTTA-3'). Hybridization and signal detection were performed using Amersham Gene Images AlkPhos Direct Labelling and Detection System (GE, UK). The hybridized signals were visualized by exposure to Fuji X-ray film at room temperature for $4 \mathrm{~h}$. 

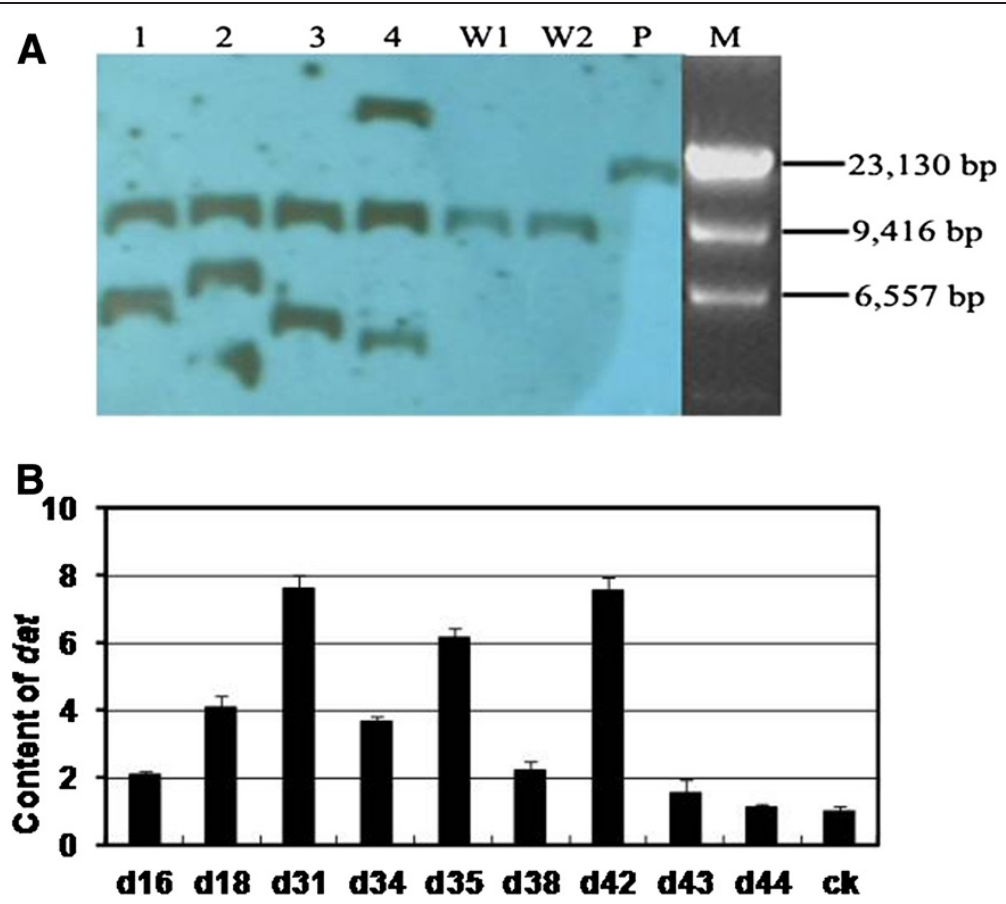

Figure 7 Analyses of DAT expression independent transgenic DAT C. roseus using southern-blot and real-time PCR. A. Southern blot analysis of four randomly selected DAT transformants. Genomic DNA of transformants (1-4), the wild-type DNA (W1, W2) and the plasmid P2301 + DAT (P) digested with BamHI were used in southern blot analysis. M, $\lambda$-Hind $\beta$ Marker. B. Real-time PCR analysis for the expression level of DAT gene in kanamycin-resistant C. roseus plants regenerated by transformation with pCAMBIA2301::p35s-DAT-nos. d16-d44, DAT transgenic plants; $c k$, average content for 15 control plants. The experiments were repeated at least 8 times and the same results were obtained.

In this work, the parameters of $A$. tumefaciens cell density, acetosyringone concentration, sonication condition and kanamycin concentration were investigated. Each treatment has three flasks replicates and each flask contains at least 20 explants. The data was analyzed with SAS software. The values are expressed as the mean of triplicate and analyzed by Duncan's New Multiple Range Test (DNMRT) with P value of 0.05 .

\section{Validation of the established transformation system}

After 3 months of the regenerated C. roseus growing in greenhouse, three pair leaves at the top of the transgenic

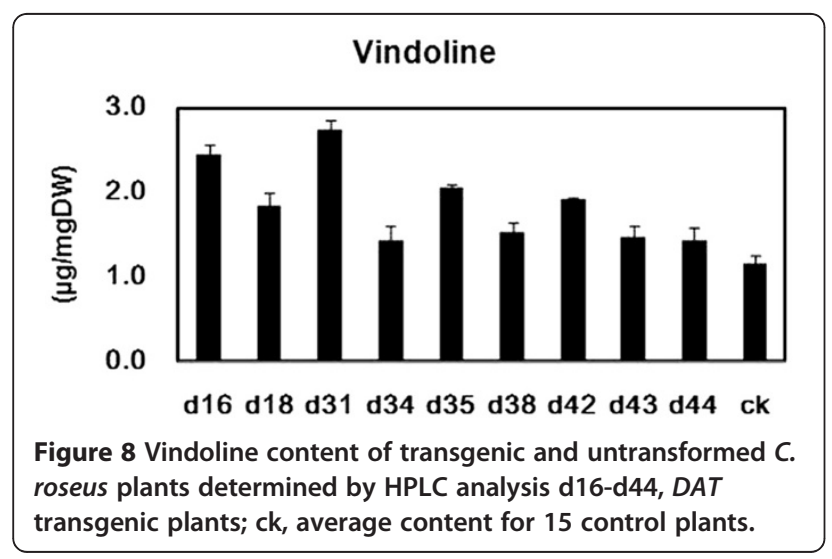

C. roseus plants and control were collected and mixed, which were used for the analysis of real-time PCR and HPLC. DAT cDNA was cloned by RT-PCR using RNA extracted with Plant (Leaves) Total RNA Isolation Kit (Watson Biotechnologies, Inc, Shanghai, China). In RTPCR, DAT-F (5'-CCCATGGGATGGAGTCAGGAAAA ATATCG-3/, with NcoI site) and DAT-R (5'-CGGTAAC CTTAATTAGAAACAAATTGAAGTAGC-3' ${ }^{\prime}$, with BstEII site) were used as the forward and reverse primer respectively, and the parameters used during PCR reaction were as follows: $94^{\circ} \mathrm{C}, 5 \mathrm{~min} ; 32$ cycles: $94^{\circ} \mathrm{C}, 30 \mathrm{~s} ; 52^{\circ} \mathrm{C}, 30 \mathrm{~s}, 72^{\circ} \mathrm{C}$, $30 \mathrm{~s} ; 72^{\circ} \mathrm{C}, 5 \mathrm{~min}$. The amplified fragment was cloned into pMD18-T vector (TakKaRa, Japan) and sequenced. After confirmation by sequencing, the pMD18-DAT was doubledigested by NcoI and BstEII, and then ligated into the NcoI and BstEII sites of pCAMBIA2301. The resultant plasmid pCAMBIA2301-35 S::DAT::NOS was then transferred into $A$. tumefaciens strain EHA105, and the resulting strains were used in the transformation of $C$. roseus. Transgenic $D A T C$. roseus plants were obtained using the same transformation procedure.

Southern blot analysis was carried out using a biotinlabelled 335 bp DAT fragment (DAT FII: 5'-GCTAT TGTTCAACTAAGTCAT-3' and DAT RII: 5'-GCAGT CAAAACCTCTACTCGAG-3') as probe. Genomic DNA of randomly selected transgenic plants and a control 
plant were digested with BamHI. The probe labelling and hybridization was also performed as previously described. The expression level of DAT was detected by real-time PCR in which the detail procedures were shown as in our previous study [28]. Briefly, the specific primers for their corresponding genes were analyzed, which include DAT-FIII (5'-CTTCTTCTCATCACG TACCAACTC-3') and DAT-RIII (5'-ATACCAAACT CAACGGCCTTAG-3') for DAT gene, and Rps9-F (5'TCGCAACTATGGTAAGACCT-3') and Rps9-R (5'-CT GTTCATCCTCCTCAAAAG-3') for Rps9 gene. The cDNA for real-time PCR was synthesized from RNA samples using Prime Script ${ }^{\mathrm{TM}}$ Reverse Transcriptase Reagent with oligo (dT) as primer according to the manufacturer's instruction (TaKaRa, Japan). The real-time PCR analysis was performed in Peltier Thermal Cycler PTC200 (BioRad, USA) using the cDNAs as templates. SYBR Premix Ex Taq (TaKaRa, Japan) was used in PCR reactions to quantify the amount of dsDNA. The relative $\mathrm{Ct}$, the threshold of cycle value, was used to estimate the initial amount of template in reactions.

To prepare the samples for HPLC, the young leaves of transgenic C. roseus were dried at $45^{\circ} \mathrm{C}$ for $48 \mathrm{~h}$ and pulverized in a mortar [29]. Then $200 \mathrm{mg}$ of each sample were immersed with $1 \mathrm{~mL}$ methanol for $10 \mathrm{~min}$. The tubes were dipped into ultrasonic bath with the power of $80 \mathrm{~W}$ for $60 \mathrm{~min}$. The mixture was centrifuged at $12,000 \mathrm{rpm}$ for $10 \mathrm{~min}$ and the supernatant was filtered with $4 \mu \mathrm{m}$ filter membrane. The extracts were stored at $4^{\circ} \mathrm{C}$.

For HPLC analysis, the commercialized vindoline (Sigma-Aldrich, USA) was prepared at a concentration of $1 \mathrm{mg} / \mathrm{L}$ in methanol and used as standard [30]. The HPLC analysis was performed using a Sapphire-C18 (4.6 $\mathrm{mm} \times 250 \mathrm{~mm}, 5 \mu \mathrm{m})$ column at a column temperature of $35^{\circ} \mathrm{C}$ and Hitachi L-2000 series HPLC system. This system consists of an L-2000 Organizer, an L-2130 Pump, an L-2200 AutoSampler, an L-2301 Column Oven and an L-2455 Diode Array Detector. The injected samples $(10 \mu \mathrm{L})$ were detected at $220 \mathrm{~nm}$ by L2455 Diode Array Detector. The mobile phase (acetonitrile and diethylamine buffer solution; 1:1) was used at a constant flow rate of $1 \mathrm{~mL}$ per min. The UV absorbance of standards and alkaloids were acquired. At last, the amount of vindoline was determined by using regression equation of calibration curve [29]. The TIAs level was determined by the areas of peak in chromatographic profile at $14.41 \mathrm{~min}$ for vindoline.

\section{Competing interests}

Do you hold any stocks or shares in an organization that may in any way gain or lose financially from the publication of this manuscript, either now or in the future? If so, please specify. No.

Do you hold or are you currently applying for any patents relating to the content of the manuscript? Have you received reimbursements, fees, funding, or salary from an organization that holds or has applied for patents relating to the content of the manuscript? If so, please specify. We have applied a patent regarding the Catharanthus roseus transformation method. We do not receive reimbursements, fees, funding from an organization (Shanghai Jiao Tong University, SJTU, the inventor's working institution) that applied for patent relating to the content of the manuscript, but only receive salary. Do you have any other financial competing interests? If so, please specify. Non-financial competing interests. No.

Are there any non-financial competing interests (political, personal, religious, academic, ideological, intellectual, commercial or any other) to declare in relation to this manuscript? If so, please specify. No.

\section{Authors' contributions}

QW performed all experiments, data analysis, and the manuscript preparation. SX took part in the experiments of Southern blot. QP, FY, YT, JZ and GW took part in the experiments of tissue culture and optimization of the transformation parameters. YC provided technical support of HPLC. KT supervised the study. All authors have read and approved the final manuscript.

\section{Acknowledgements}

Research project funding was from China National High-Tech "863" Program (grant number 2011AA100605), Shanghai Science and Technology Committee (grant number 08391911800) and Shanghai Leading Academic Discipline Project (Project Number: B209).

Received: 5 September 2011 Accepted: 11 May 2012

Published: 29 June 2012

\section{References}

1. Facchini PJ, De Luca V: Opium poppy and Madagascar periwinkle: model non-model systems to investigate alkaloid biosynthesis in plants. Plant J 2008, 54(4):763-784.

2. van Der Heijden R, Jacobs DI, Snoeijer W, Hallard D, Verpoorte R: The Catharanthus alkaloids: pharmacognosy and biotechnology. Curr Med Chem 2004, 11(5):607-628.

3. Noble RL: The discovery of the vinca alkaloids-chemotherapeutic agents against cancer. Biochem Cell Biol 1990, 68(12):1344-1351.

4. Magnotta M, Murata J, Chen J, De Luca V: Expression of deacetylvindoline4-O-acetyltransferase in Catharanthus roseus hairy roots. Phytochemistry 2007, 68(14):1922-1931.

5. Yang L, Stöckigt J: Trends for diverse production strategies of plant medicinal alkaloids. Nat Prod Rep 2010, 27(10):1469-1479.

6. Loyola-Vargas VM, Galaz-Ávalos RM, Kú-Cauich R: Catharanthus biosynthetic enzymes: the road ahead. Phytochem Rev 2007, 6(2-3):307339.

7. Choi PS, Kim YD, Choi KM, Chung HJ, Choi DW, Liu J: Plant regeneration from hairy-root cultures transformed by infection with Agrobacterium rhizogenes in Catharanthus roseus. Plant Cell Rep 2004, 22(11):828-831.

8. Peebles CAM, Sander GW, Hughes EH, Peacock R, Shanks JV, San KY: The expression of 1-deoxy-D-xylulose synthase and geraniol-10-hydroxylase or anthranilate synthase increases terpenoid indole alkaloid accumulation in Catharanthus roseus hairy roots. Metab Eng 2011, 13 (2):234-240.

9. van der Fits L, Memelink J: Comparison of the activities of CaMV $35 \mathrm{~S}$ and FMV $34 \mathrm{~S}$ promoter derivatives in Catharanthus roseus cells transiently and stably transformed by particle bombardment. Plant Mol Biol 1997, 33 (5):943-946.

10. Hilliou F, Christou P, Leech MJ: Development of an efficient transformation system for Catharanthus roseus cell cultures using particle bombardment. Plant Sci 1999, 140(2):179-188.

11. Zárate R, Memelink J, van der Heijden R, Verpoorte R: Genetic transformation via particle bombardment of Catharanthus roseus plants through adventitious organogenesis of buds. Biotechnol Lett 1999, 21 (11):997-1002

12. Guirimand G, Burlat V, Oudin A, Lanoue A, St-Pierre B, Courdavault V: Optimization of the transient transformation of Catharanthus roseus cells by particle bombardment and its application to the subcellular localization of hydroxymethylbutenyl 4-diphosphate synthase and geraniol 10-hydroxylase. Plant Cell Rep 2009, 28(8):1215-1234. 
13. Canel C, Lopes-Cardoso MI, Whitmer S, van der Fits L, Pasquali G, van der Heijden R, Hoge JHC, Verpoorte R: Effects of over-expression of strictosidine synthase and tryptophan decarboxylase on alkaloid production by cell cultures of Catharanthus roseus. Planta 1998, 205 (3):414-419.

14. Whitmer S, Canel C, van der Heijden R, Verpoorte R: Long-term instability of alkaloid production by stably transformed cell lines of Catharanthus roseus. Plant Cell Tiss Org Cult 2003, 74(1):73-80.

15. Srivastava T, Das S, Sopory SK, Srivastava PS: A reliable protocol for transformation of Catharanthus roseus through Agrobacterium tumefaciens. Physiol. Mol. Biol. Plants 2009, 15(1):93-98.

16. Verma P, Mathur AK: Agrobacterium tumefaciens-mediated transgenic plant production via direct shoot bud organogenesis from preplasmolyzed leaf explants of Catharanthus roseus. Biotechnol Lett 2011, 33 (5):1053-1060.

17. Trick HN, Finer JJ: SAAT: sonicated-assisted Agrobacterium-mediated transformation. Transgenic Res 1997, 6(5):329-336(8).

18. Finer KR, Finer JJ: Use of Agrobacterium expressing green fluorescent protein to evaluate colonization of sonication-assisted Agrobacteriummediated transformation-treated soybean cotyledons. Lett Appl Microbiol 2000, 30(5):406-410

19. Santarém ER, Trick HN, Essig JS, Finer JJ: Sonication assisted Agrobacterium-mediated transformation of soybean immature cotyledons: optimization of transient expression. Plant Cell Rep 1998, 17 (10):752-759.

20. Liu Z, Park BJ, Kanno A, Kameya T: The novel use of a combination of sonication and vacuum infiltration in Agrobacterium-mediated transformation of kidney bean (Phaseolus vulgaris L.) with lea gene. Mol Breed 2005, 16:189-197.

21. Park BJ, Liu Z, Kanno A, Kameya T: Transformation of radish (Raphanus sativus L.) via sonication and vacuum infiltration of germinated seeds with Agrobacterium harboring a group 3 LEA gene from B. napus. Plant Cell Rep 2005, 24(8):494-500.

22. Beranová M, Rakouský S, Vávrová Z, Skalický T: Sonication assisted Agrobacterium-mediated transformation enhances the transformation efficiency in flax (Linum usitatissimum L). Plant Cell Tiss Org cult 2008, 94 (3):253-259.

23. Pathak MR, Hamzah RY: An effective method of sonication-assisted Agrobacterium-mediated transformation of chickpeas. Plant Cell Tiss Org cult 2008, 93(1):65-71.

24. Murashige T, Skoog F: A revised medium for rapid growth and bioassay with tobacco tissue cultures. Physiol Plant 1962, 15:473-497.

25. Hiei $Y$, Komari T: Agrobacterium-mediated transformation of rice using immature embryos or calli induced from mature seed. Nat Protoc 2008, 3 (5):824-834.

26. Jefferson RA, Kavanagh TA, Bevan MW: Gus fusions: $\beta$-glucuronidase as a sensitive and versatile gene fusion marker in higher plants. EMBO J 1987, 6(13):3901-3907.

27. Murray MG, Thompson WF: Rapid isolation of high molecular weight plant DNA. Nucleic Acids Res 1980, 8(19):4321-4325.

28. Wang Q, Yuan F, Pan Q, Li M, Wang G, Zhao J, Tang K: Isolation and functional analysis of the Catharanthus roseus deacetylvindoline-4-Oacetyltransferase gene promoter. Plant Cell Rep 2010, 29(2):185-192.

29. Pan $Q$, Chen Y, Wang Q, Yuan F, Xing S, Tian Y, Zhao J, Sun X, Tang K: Effect of plant growth regulators on the biosynthesis of vinblastine vindoline and catharanthine in Catharanthus roseus. Plant Growth Regul 2010, 60(2):133-141.

30. Hisiger S, Jolicoeur M: Analysis of Catharanthus roseus alkaloids by HPLC. Phytochem Rev 2007, 6:207-234.

doi:10.1186/1472-6750-12-34

Cite this article as: Wang et al:: Development of efficient catharanthus roseus regeneration and transformation system using agrobacterium tumefaciens and hypocotyls as explants. BMC Biotechnology 2012 12:34.

\section{Submit your next manuscript to BioMed Central and take full advantage of:}

- Convenient online submission

- Thorough peer review

- No space constraints or color figure charges

- Immediate publication on acceptance

- Inclusion in PubMed, CAS, Scopus and Google Scholar

- Research which is freely available for redistribution

Submit your manuscript at www.biomedcentral.com/submit
C BioMed Central 